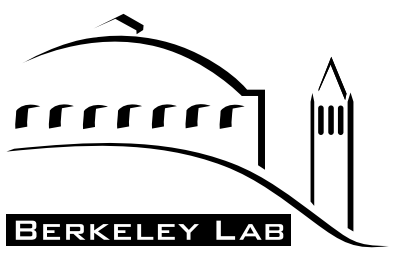

LBNL/PUB-5478-Rev.B

\title{
Large Hadron Collider (LHC) Project Quality Assurance Plan
}

\section{Accelerator and Fusion Research Division Ernest Orlando Lawrence Berkeley National Laboratory} September 2002 
Date

Prepared by: Lisa Gullo

Date

William Turner, LBNL LHC Project Manager

Date

Victor Karpenko, Mechanical Engineering Department Head

Date

Kem E. Robinson, General Sciences/AFRD

REVISION HISTORY

\begin{tabular}{|l|l|l|}
\hline $\begin{array}{c}\text { Rev. } \\
\text { No. }\end{array}$ & \multicolumn{1}{|c|}{ Date } & \multicolumn{1}{c|}{ Description } \\
\hline A & 20 August 2002 & Added sentence to 2.6 and Added Section 2.7 \\
\hline B & $\begin{array}{l}\text { 04 September } \\
2002\end{array}$ & $\begin{array}{l}\text { Notations added and section numbers updated on cross reference table; Text } \\
\text { added to relevant sections }\end{array}$ \\
\hline & & \\
\hline & & \\
\hline & & \\
\hline & & \\
\hline & & \\
\hline
\end{tabular}


It is the policy of the Ernest Orlando Lawrence Berkeley National Laboratory to carry out all our activities that contribute to the scientific and operational objectives of the Large Hadron Collider (LHC) Project in a reliable, safe, and quality focused manner. The LHC Quality Assurance Plan (LHC/QAP) provides the framework for a results-oriented management system that focuses on performing work safely and meeting mission and customer expectations efficiently through process improvement. It is line management's responsibility to plan for and achieve compliance with the objectives of the LHC/QAP. In addition, every Berkeley Lab employee is individually responsible for the quality and safety of his or her work.

It is our policy to implement the LHC/QAP in a way that is adequate to enable compliance with DOE contract requirements, that ensures our continued scientific research and programmatic success, and that is resourceefficient. Our program emphasizes three principles:

- The most essential resources at Berkeley Lab are the creative scientists, engineers, and support personnel.

- People who perform the work have the greatest effect on outcome and process quality.

- Problem prevention is more cost-effective than problem correction.

Accordingly, our program establishes a management system that (1) recognizes that managing a laboratory that supports research is different from managing the research itself and (2) provides a process for continuous improvement in our performance in both aspects of Laboratory management.

Each of us has a critical role to play in the achievement of our institutional objectives. This program is designed to aid all of us, including our partners at DOE, in that effort.

William A. Barletta

Director

Accelerator and Fusion Research Division

Ernest Orlando Lawrence

Berkeley National Laboratory 


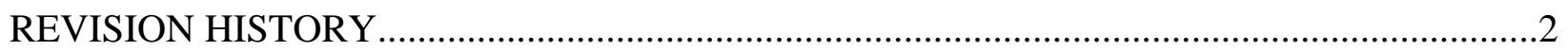

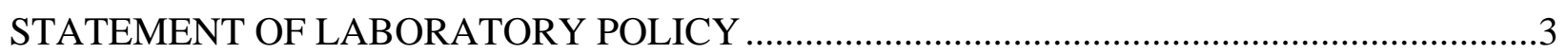

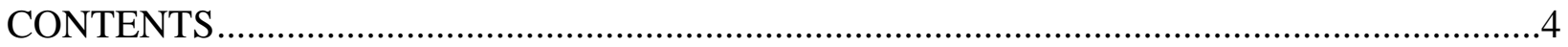

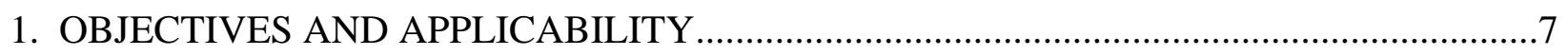

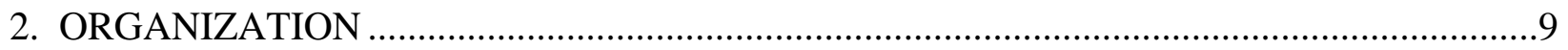

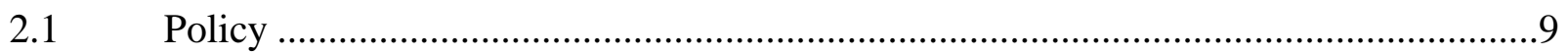

2.2 Organizational Structure .................................................................................

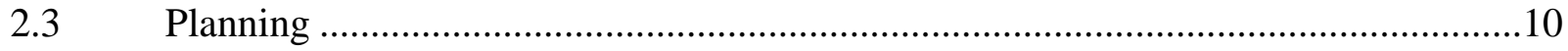

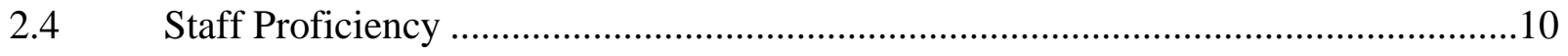

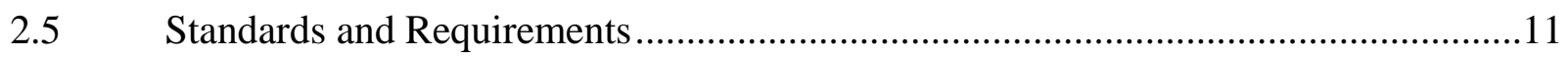

$2.6 \quad$ Reference Documents ........................................................................................

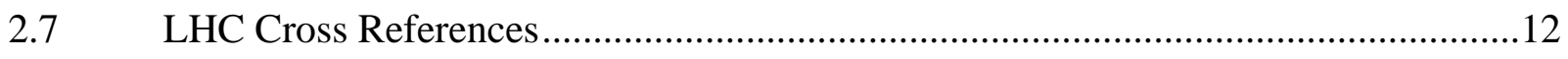

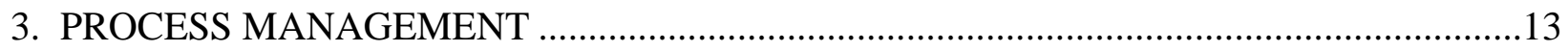

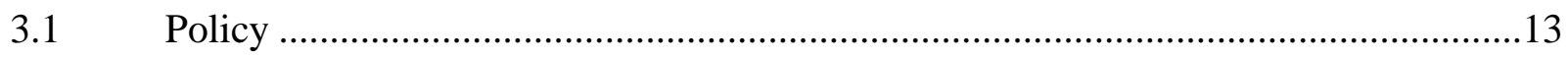

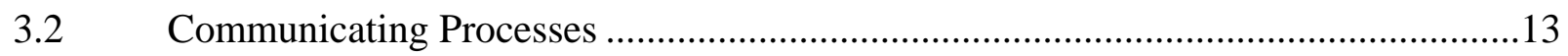

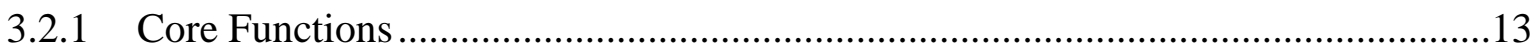

3.2.2 Written Procedures, Instructions, and Drawings ....................................................13

3.3 Integrated Safety Management ………………....................................................

3.3.1 Hazards and Risks in the Work Process ................................................................14

3.3.2 Work Authorization .........................................................................................15

3.3.3 Stopping Unsafe Work...................................................................................16

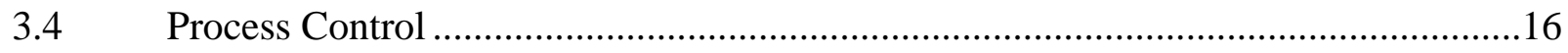

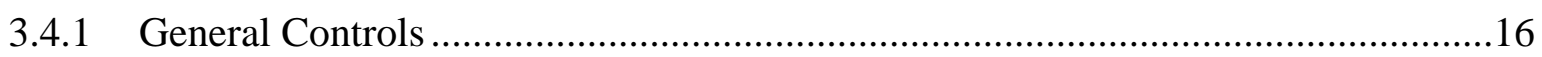

3.4.2 Suspect/Counterfeit Items ............................................................................16

3.4.3 Function-Specific Controls .................................................................................18

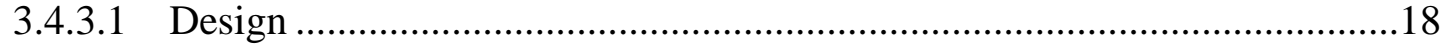

3.4.3.2 Procurement ............................................................................................19

3.4.3.3 Inspection and Testing ............................................................................20

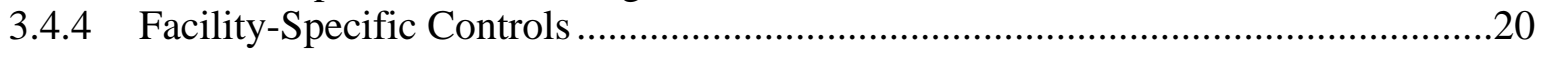

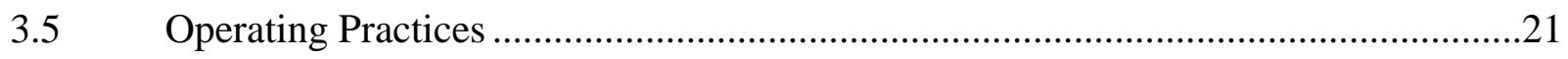

3.5.1 Facility Practices.........................................................................................21

3.5.2 Asset Management...........................................................................................21

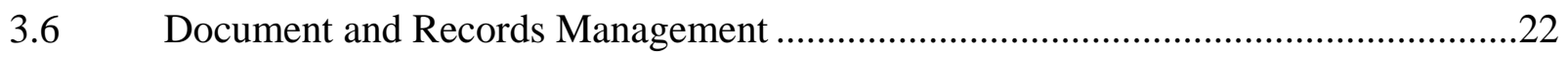


4. PERFORMANCE ASSESSMENT AND IMPROVEMENT ............................................24

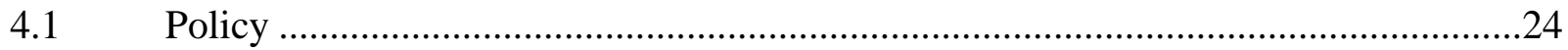

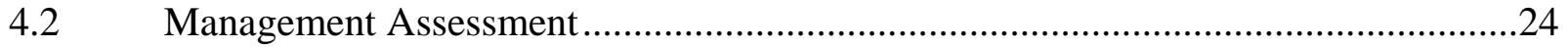

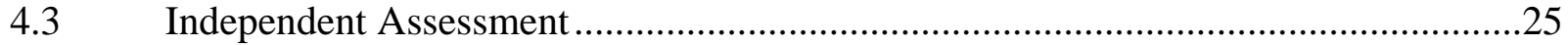

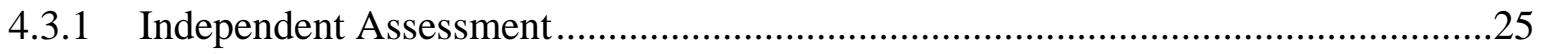

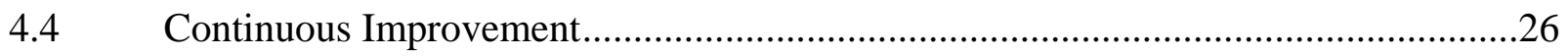

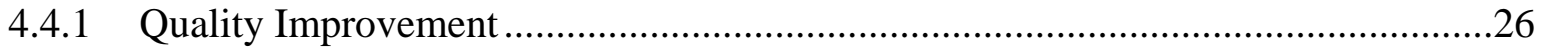

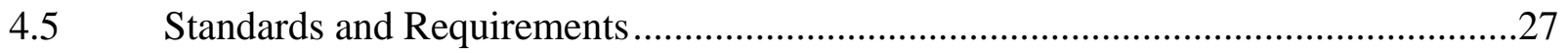

APPENDIX A: GRADED APPROACH METHODOLOGY AT BERKELEY LAB................28

Table A-1: Risk Potential Analysis Using the Berkeley Lab Priority Planning Grid..............30

APPENDIX B: PRINCIPAL LBNL US-LHC PROJECT STAFF...........................................31

\section{APPENDIX C: LHC QA PROCEDURES FOR USE DURING PROCUREMENT,}

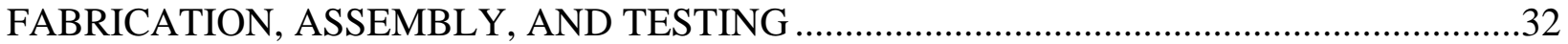

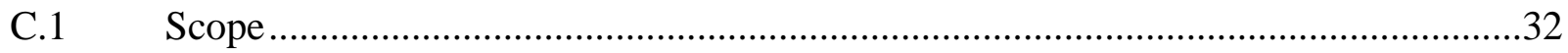

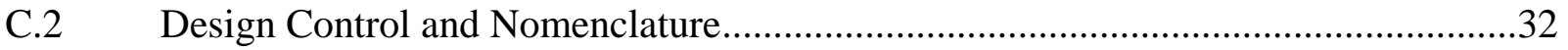

C.2.1 Design Document Flow...............................................................................33

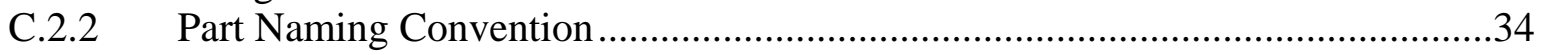

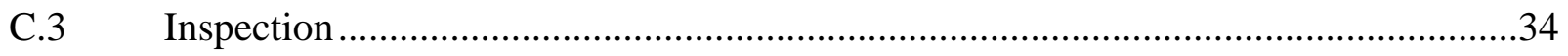

C.3.1 Procured Parts and Assemblies …..............................................................34

C.3.2 LBNL Fabricated Parts/Assemblies .............................................................34

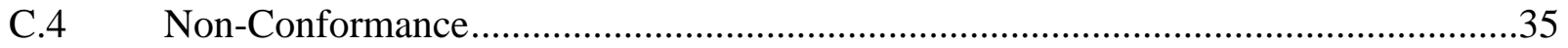

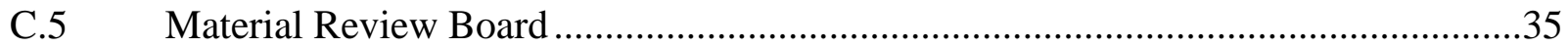

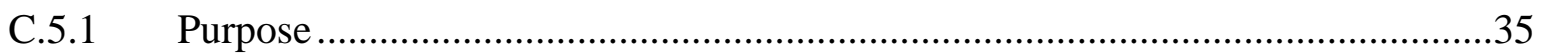

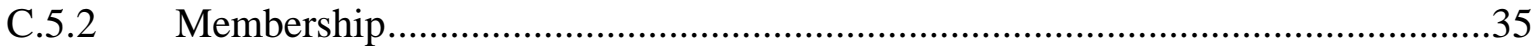

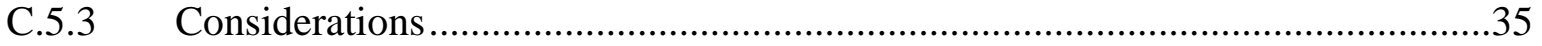

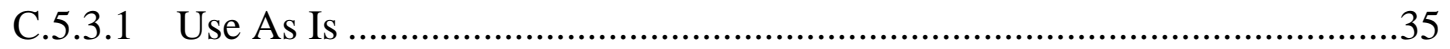

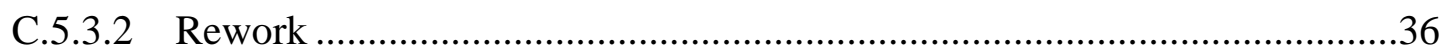

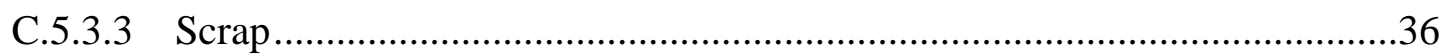

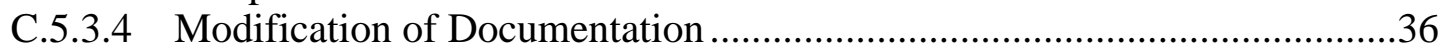

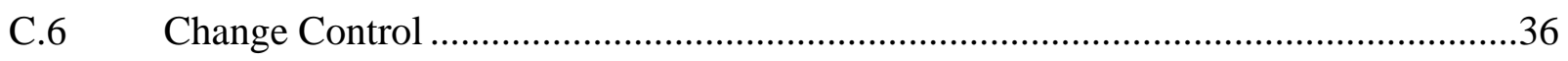

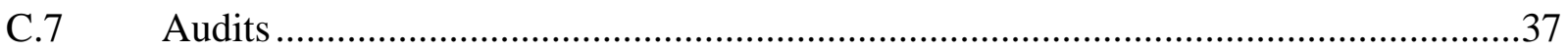

APPENDIX D: INTEGRATED SAFETY MANAGEMENT ..................................................38

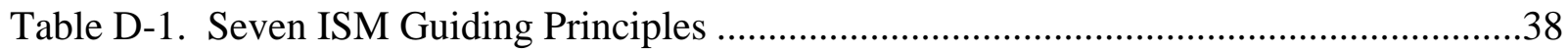

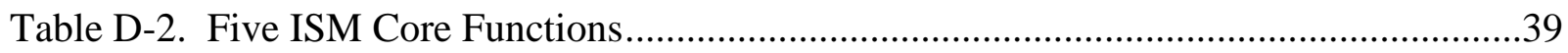

APPENDIX E: POLICY AND PROCEDURE FOR CONTROLLING

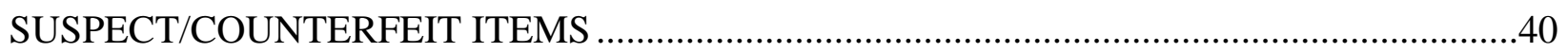

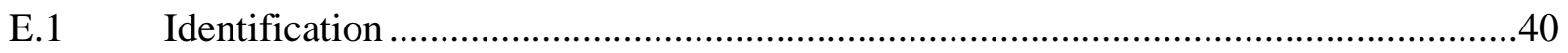




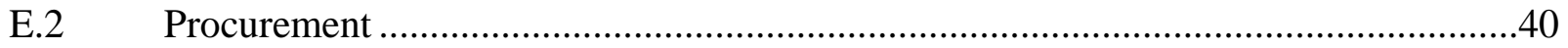

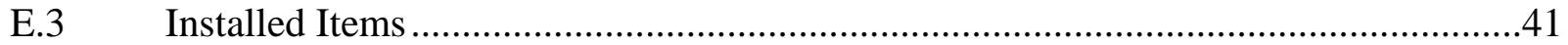

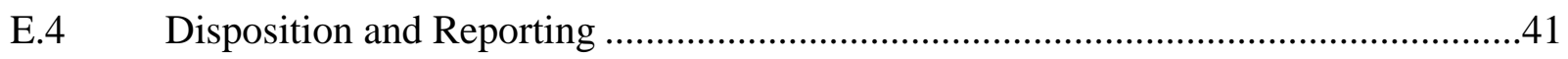




\section{SECTION 1}

\section{OBJECTIVES AND APPLICABILITY}

The LHC Quality Assurance Plan is a set of operating principles, requirements, and practices used to support Berkeley Lab's participation in the Large Hadron Collider Project. The LHC/QAP is intended to achieve reliable, safe, and quality performance in the LHC project activities. The LHC/QAP is also designed to fulfill the following objectives:

- The LHC/QAP is Berkeley Lab’s QA program document that describes the elements necessary to integrate quality assurance, safety management, and conduct of operations into the Berkeley Lab's portion of the LHC operations.

- The LHC/QAP provides the framework for Berkeley Lab LHC Project administrators, managers, supervisors, and staff to plan, manage, perform, and assess their Laboratory work.

- The LHC/QAP is the compliance document that conforms to the requirements of the Laboratory's Work Smart Standards for quality assurance (DOE O 414.1, 10 CFR 830.120), facility operations (DOE O 5480.19), and safety management (DOE P 450.4).

The LHC/QAP is applicable to all Berkeley Lab work related to the LHC Project. All Berkeley Lab involved units should be engaged, at some level, with organizing their resources, managing and ensuring the safety of their processes and activities, and evaluating the results of their performance. However, the level of rigor in applying the LHC/QAP principles, requirements, and practices is based on a graded approach, with consideration given to the organization's mission, its programmatic or operational significance, and its environmental, safety, and health consequences to personnel, environment, and the general public. Appendix A contains one methodology that can be used to grade processes, activities, and facilities to determine the applicable level of rigor. Alternate methodologies, such as the use of DOE guidance documents or evaluation of existing hazard documentation, may be used if the rationale is appropriately documented and approved.

Implementing the LHC/QAP requires involved Berkeley Lab organizations to maintain documents and/or electronic web sites that describe the organization, mission, and scope of work. The LHC/QAP is implemented for radiological facilities through the Radiation Protection Program in order to meet the quality assurance requirements of 10 CFR 830.120 
http://www.lbl.gov/ehs/oap/html/standards.htm . Programs in waste management, environmental restoration, and environmental monitoring (NESHAP) require program- or site-specific quality assurance plans.

The goal and objective of this document, the policy that it represents and the guiding philosophy of LBNL and the Accelerator and Fusion Research Division is to ensure that an optimum level of formalism, documentation, procedures, and direction exist to ensure that that equipment, drawings, software, or other deliverables serves its intended purpose in furthering the scientific goals and mission of the Department of Energy. Such deliverables are to function in a reliable manner and integrate in an appropriate fashion with all agreements, controlling documents and interface specifications governing the deliverables provided by Berkeley Lab.

\section{Office of Assessment and Assurance}

The Office of Assessment and Assurance (OAA) http://www.lbl.gov/ehs/oaa/ is the Laboratory organization that supports the LHC/QAP. OAA provides the following services:

- Advises and supports Berkeley Lab involved units on issues related to quality assurance, integrated safety management, and conduct of operations.

- For involved units requiring more rigorous controls, assists in preparing program- or site-specific quality assurance plans, implementation plans, operating manuals, and/or similar documents.

- Conducts appraisals to evaluate the effectiveness of the LHC/QAP in Berkeley Lab operations.

- Assist in maintaining the LHC/QAP.

These OAA services, as an integral part of the Berkeley Lab management system, ensure that quality assurance, safety, and conduct of operations are implemented effectively at Berkeley Lab. 


\section{SECTION 2}

ORGANIZATION

\subsection{Policy}

Berkeley Lab LHC-involved units must:

- Describe their organizational structure, functional responsibilities, levels of authority, and interfaces.

- Plan for their functions and activities to deliver safe, reliable, and quality products and services.

- Hire and retain staff proficient to perform their functions and activities.

An appropriate management structure, a proficient staff, and a systematic approach in planning work are key elements in sustaining both a safe and high level of performance. This section describes the steps for implementing these concepts.

\subsection{Organizational Structure}

The Laboratory is, in general, organized hierarchically by divisions, departments, groups, and offices. A description of the organization must be maintained for each of these levels. This information is the basis for identifying the functional responsibilities, levels of authority, and interfaces both within and between organizations. LHC organizational information must be clearly communicated to all affected Lab personnel.

The LBNL-LHC effort includes the following:

1 Provide Accelerator Physics Support to CERN

2 Provide Superconducting Cable and Support to FNAL and CERN

3 Design, fabricate, and ship TAS \& TAN Thermal Absorbers to CERN

4 Design, fabricate, and ship DFBX Cryogenic Feedboxes to CERN

Appendix B lists the current principal staff of the LBNL-USLHC Project.

Roles, responsibilities, and authorities of managers and staff must be clearly defined in position descriptions and/or job expectations. Environment, 
safety, and health responsibilities and duties should be part of the description and expectation.

\subsection{Planning}

Planning is a systematic approach used to identify in advance the parameters and actions necessary to execute or arrange an activity, function, or project. It is an ongoing process that begins as early as practical, to allow sufficient time to address such issues as the following:

- Funding

- Organizational interfaces and authorities

- Resource allocation

- Requirements for written procedures and drawings

- Identification of safety standards and requirements

- Identification of security requirements and controls

- Training needs for staff

Good planning generally results in higher efficiency, effectiveness, safety, and quality in products and services.

Berkeley Lab utilizes MS Project and Millenium software for developing and tracking LBNL-USLHC Project milestones. Each month the LHC budget is reported using the earned value system. Scheduled tasks are broken down to five levels, the fifth level being the most detailed. Gantt charts are used whenever the LBNL-USLHC Project is re-baselined.

Planning by the LBNL-USLHC Project includes the following meetings as appropriate:

- Weekly Staff Operation and Planning meetings

- Weekly DFBX Design Meetings

- Design Reviews, both internal and external

- Monthly tracking of cost and schedule against the project baseline

- Monthly AFRD ES\&H meetings

\subsection{Staff Proficiency}

Staff proficiency involves hiring and retaining staff that have the appropriate skills, experience, and qualifications to carry out their work assignments successfully and safely. To ensure consistent hiring practices, the Berkeley Lab Human Resources Department provides the institutional policies and procedures for personnel qualification, selection, and training. [See the Berkeley Lab Regulations and Procedures Manual (RPM) http://www.lbl.gov/LBL-Work/RPM/StyleGuide.html, Section 2.00, Personnel.] Berkeley Lab LHC-involved supervisors and managers must follow these requirements in hiring new staff. 
Supervisors and managers ensure that the following activities related to staff proficiency are accomplished and documented for each individual assigned to the LBNL-USLHC Project:

- Position Descriptions established by LBNL divisions must be consistent with the requirements of the LBNL-USLHC.

- Training needs for each position are determined by completion of the LBNL Job Hazard Questionnaire which addresses ES\&H issues and special training to allow the individual to carry out the job duties in an efficient manner. The need for special training is determined by a combination of the employee, LBNL-USLHC supervisor, or matrix organization supervisor.

- Job orientation, ES\&H training, required reading, and on-the-job training must be completed as early as possible after the job assignment. Some training is required prior to the actual performance of work. Onthe-job training must be administratively controlled to ensure that such training is not allowed to affect workplace or operational safety (see RPM 2.01, 2.04).

- Periodic training and retraining must be provided to ensure continued job proficiency and to improve overall performance and safety (see RPM 2.04).

- Performance evaluations must be conducted at least annually for every position to ensure that job proficiency is being maintained and improved. The performance evaluations are retained by the matrix organization.

\subsection{Standards and Requirements}

The Objectives and Applicability and Section 1 of the LHC/QAP conform to the following quality assurance criteria described in 10 CFR 830.120, Quality Assurance Requirements, and DOE O 414.1, Quality Assurance:

- Criterion 1, Program

- Criterion 2, Personnel Training and Qualification

Section 1 also complies with requirements described in paragraph 4 of DOE O 5480.19, Chg. 1, Conduct of Operations Requirements for DOE Facilities, and DOE P 450.4, Safety Management System Policy.

\subsection{Reference Documents}

- Publication 3000 Safety Plan (See http://www.lbl.gov/ehs/pub3000/ )

- Publication 3111 Operation and Assurance Plan (See http://www.lbl.gov/ehs/oap/oap_home.htm)

- Document Control Processes (See Appendix C)

- CERN: The LHC Quality Assurance Plan (See http://www.lhc-projgawg.web.cern.ch/hc-proj-qawg/LHCQAP) 


\subsection{LHC Cross References}

The following table provides a cross reference between relevant CERN quality assurance documents and sections within this plan.

\begin{tabular}{|c|c|c|}
\hline CERN Procedure Number & Title & LHC QA Plan: Section \\
\hline LHC-PM-QA-100.00 & $\begin{array}{l}\text { Quality Assurance Policy and } \\
\text { Project Organization }\end{array}$ & $2.1 ; 2.2 ; 2.3 ; 2.4$ \\
\hline LHC-PM-QA-101.00 & $\begin{array}{l}\text { Quality Assurance Plan Contents } \\
\text { And Status }\end{array}$ & $\begin{array}{l}\text { TOC; Appendix A; } \\
\text { (LBNL uses the graded system specified } \\
\text { in Appendix A, QAC codes are added by } \\
\text { CERN.) }\end{array}$ \\
\hline LHC-PM-QA-201.00 & Quality Assurance Categories & C.6 \\
\hline LHC-PM-QA-202.00 & $\begin{array}{l}\text { Document Types and Naming } \\
\text { Conventions }\end{array}$ & 3.7; С.2; С.6 \\
\hline LHC-PM-QA-206.00 & LHC Part Identification & C. 2 \\
\hline LHC-PM-QA-301.00 & $\begin{array}{l}\text { Planning and Scheduling } \\
\text { Requirements for Institutes, } \\
\text { Contractors and Suppliers }\end{array}$ & 2.3; 3.4.3; \\
\hline LHC-PM-QA-303.00 & $\begin{array}{l}\text { Documents and Parameters } \\
\text { Process and Control }\end{array}$ & $\begin{array}{l}\text { 3.2; 3.4; 3.6; C.2; C.6; } \\
\text { Appendix B; }\end{array}$ \\
\hline LHC-PM-QA-304.00 & $\begin{array}{l}\text { Configuration Management - } \\
\text { Change Process and Control }\end{array}$ & C.6 \\
\hline LHC-PM-QA-305.00 & $\begin{array}{l}\text { Drawing and 3D Model } \\
\text { Management and Control }\end{array}$ & C.6 \\
\hline LHC-PM-QA-306.00 & $\begin{array}{l}\text { Drawing Process - External } \\
\text { Drawing }\end{array}$ & 3.6; C.2 \\
\hline LHC-PM-QA-307.00 & Design Process and Control & 3.6; C.2 \\
\hline LHC-PM-QA-308.00 & $\begin{array}{l}\text { Purchasing and Contracting } \\
\text { Process and Control }\end{array}$ & $\begin{array}{l}\text { 3.4;.3.2; E.2 } \\
\text { (LBNL follows US Federal Acquistion } \\
\text { Regulations [FAR] and Dept. of Energy } \\
\text { Acquisition Regulations [DEARs]) }\end{array}$ \\
\hline LHC-PM-QA-309.00 & $\begin{array}{l}\text { Manufacturing and Inspection } \\
\text { Equipment }\end{array}$ & C.3; E.4 \\
\hline LHC-PM-QA-310.00 & $\begin{array}{l}\text { Handling of Nonconforming } \\
\text { Equipment }\end{array}$ & C.4; E.4 \\
\hline LHC-PM-QA-402.00 & $\begin{array}{l}\text { Design Standards - Mechanical } \\
\text { Engineering and Installations }\end{array}$ & 3.7; C.2 \\
\hline LHC-PM-QA-403.00 & $\begin{array}{l}\text { Design Standards - Electrical } \\
\text { Schematic Diagrams }\end{array}$ & 3.7; C.2 \\
\hline LHC-PM-QA-405.00 & Document Standards & 3.6; 3.7; C.2 \\
\hline
\end{tabular}




\subsection{Policy}

The Berkeley Lab LHC-involved organization(s) manage their work processes by:

- Communicating clearly to affected staff the goals, objectives, and procedures of the work processes

- Identifying and mitigating the hazards and risks of the work processes

- Instituting process controls to enhance performance, quality, and safety

- Authorizing work to signify that the required procedures, controls, and resources are in place

- Establishing document and records control measures to ensure the availability of accurate information and quality assurance

A process occurs when a combination of people, materials, equipment, and actions interact to produce a given product or service. The process is managed by the application of system controls to assure the quality and safety of the product or service. This section describes the controls deemed necessary for Berkeley Lab LHC work processes.

\subsection{Communicating Processes}

\subsubsection{Core Functions}

Core functions are the key processes used to meet the organization's scientific or operational objectives. The Berkeley Lab LHC-involved organization's core functions include: accelerator physics, superconductor processing, hardware design, hardware fabrication, and hardware testing.

\subsubsection{Written Procedures, Instructions, and Drawings}

As far as possible, core functions should have written procedures, instructions, and/or drawings to direct and inform personnel how to perform the functions in an efficient and safe manner. In addition to procedures for core functions, other work activities may require similar written procedures, based on the activity's complexity, ES\&H hazard, programmatic or operational significance, and consequences to other organizations.

One-of-a-kind activities, such as accelerator physics studies or the development of designs for research equipment are generally not guided by 
explicit, written procedures. In this case, the scientist or engineer is required to have sufficient experience and expertise to identify a course of action and prepare an initial calculation or conceptual design for peers and/or the customer to review. A series of refined calculations or designs followed by reviews leads eventually to a final calculation or design.

Procedures for superconductor processing, hardware fabrication, hardware testing and other significant work processes for the LBNL-USLHC Project are written formally to ensure clarity and proper review and approval. The LHC procedures include the following:

1. Approval signatures and effective date

2. A unique title or other identifier

3. Purpose and scope

4. Definitions (for special acronyms or terms)

5. Procedural work steps with associated responsibilities and controls

6. References (sources of requirements)

Modification of approved procedures for core functions and other significant work processes require a formal change control process if the changes have an impact on the quality or function of the hardware or on the safety of the activity. Change control should include approval signatures, effective date, and revision number for the changed procedure.

Activities with low or moderate significance or consequences (as determined by the supervisor or manager) may have less formal procedures or instructions, but these must be clear and concise. Notes, desk manuals, memos, operator aids, logbooks, notebooks, postings, and drawings are acceptable methods for this level of written communication. Modification of these types of procedures requires, at a minimum, written concurrence by the immediate supervisor if the changes have an impact on the quality and safety of the activity.

Oral instruction, when it is the only communication method used, is not considered sufficient for directing and informing personnel on core functions or other significant work processes.

\subsection{Integrated Safety Management}

\subsubsection{Hazards and Risks in the Work Process}

Safety must be integrated into the work process. For all core functions and other significant activities, the LHC-involved managers must implement an integrated safety management process as outlined in Appendix D to ensure that safety-related work issues have been addressed comprehensively. At a minimum, line management must have auditable evidence of the identification and control of hazards in their responsible workplace. 
Managers must follow the requirements in Chapter 6 of PUB-3000, the Berkeley Lab Health and Safety Manual, to identify hazards and implement appropriate controls. Berkeley Lab’s Environment, Health and Safety Division (EH\&S) provide the support and guidance to the LHC-involved managers for identifying and mitigating the hazards in their workplaces.

All LHC-involved managers must perform the following safety functions:

- Define the scope of work.

- Analyze the hazards.

- Develop and implement controls.

- Perform work within the controls.

- Provide feedback and continuous improvement.

Documentation of the above functions can be in work plans, Division ES\&H reports, or authorization/contract agreements.

\subsubsection{Work Authorization}

Depending on the programmatic or operational significance and environment, safety, and health consequences, some work processes such as pressure testing, high voltage testing, and tests using cryogenic fluids may require formal work authorization from the management of Berkeley Lab organizations. Formal authorization is a review and approval process by management to ensure that procedures, controls, and resources are in place before the work begins. Formal authorization results in a written document that describes

- The scope of work

- Required procedures and controls

- Authorized materials and equipment to be used

- Authorized staff to conduct the work

The document must be signed off by the appropriate manager(s) and/or staff to signify approval of such work.

When formal authorization is not warranted based on a graded approach, line managers must still review and approve work under their supervision. Line authorization need not be formalized into an authorization document. Work plans, position descriptions, and job expectations are acceptable vehicles for line authorization.

Regardless of the type of authorization, all LHC-involved managers and staff must consider the following work principles in the review and approval of their work:

- Line management accountability

- Clear roles and responsibilities

- Competence commensurate with responsibilities

- Balanced priorities

- Identification of work and safety standards

- Conditions and requirements for performing work 
- Work and hazard controls tailored to the work being performed

\subsubsection{Stopping Unsafe Work}

All LHC-involved employees, contractors, and participating guests are responsible for stopping work activities considered to be an imminent danger. Stopping unsafe work applies to all activities conducted at the Laboratory and to all offsite facilities operated by Laboratory personnel. An "imminent danger" is defined as any conditions or practices that could reasonably be expected to cause death or serious injury, or environmental harm. Whenever an employee, contractor, or participating guest encounters conditions or practices that appear to constitute an imminent danger, such individuals have the authority and responsibility to:

- Alert the affected employee(s) engaged in the unsafe work creating an imminent-danger condition, and request that the work be stopped.

- Call Berkeley Lab's emergency telephone number (x7911) and report the incident. The EH\&S Duty Officer will be notified through this contact.

- Notify the immediate supervisor and/or responsible division/department manager (if known).

The EH\&S Duty Officer will ensure that the supervisor is notified and will assist the supervisor in preparing a report to the EH\&S Division Director, describing the unsafe activity and identifying corrective actions and responsibilities.

\subsection{Process Control}

\subsubsection{General Controls}

Process control is intended to reduce variation in the work process, thereby improving performance, safety, and quality. LHC-involved line managers must review their core functions and other significant activities to ensure that appropriate controls are in place. Examples of process controls include:

- Check points in the process where management review and approval are required

- Use of safety standards and requirements necessary and sufficient to mitigate the hazards of the work process

- Assurance that only the appropriate equipment and material are used

- Assurance that up-to-date written procedures to direct the work are being used (see Section 2.2.2)

- Acceptance criteria for final review of end product or service

\subsubsection{Suspect/Counterfeit Items}

LHC-involved line managers must be cognizant of the presence of suspect/counterfeit items (S/CIs) in their work processes. A suspect item is one in which there is an indication by visual inspection, testing, or other information that it may not conform to established government or industryaccepted specifications or national consensus standards. A counterfeit item is a suspect item that is a copy or substitute without legal right or authority to 
do so, or one whose material, performance, or characteristics are knowingly misrepresented by the vendor, supplier, distributor, or manufacturer. The use of suspect/ counterfeit items can lead to unexpected failures and undue risk of mission impacts, environmental impacts, and personal injury, contamination, or death.

To mitigate the use of suspect/counterfeit items in LHC-related work processes, line managers must implement the Laboratory Policy and Procedure for Controlling S/CIs, as described in Appendix E. The controls include:

- Guidance on identifying S/CIs

- Procurement procedures to prevent the purchase of S/CIs

- Detection and disposition of S/CIs from Laboratory facilities and installed equipment

- Reporting requirements for discovered S/Cis 


\subsubsection{Function-Specific Controls}

The LBNL-USLHC Project has the following function-specific controls in place:

\subsubsection{Design}

\begin{tabular}{|c|c|c|}
\hline Activity & Application & Con \\
\hline Input & $\begin{array}{c}\text { TAN/TAS \& DFBX } \\
\text { design }\end{array}$ & $\begin{array}{l}\text { - Identify and record: } \\
\text { - Functional Specifications } \\
- \text { Applicable codes, standards, and regulatory requirements as } \\
\text { stated in the USLHC-CERN MOU } \\
\text { - } \text { ES\&H considerations } \\
\text { - } \\
\text { Reviews conducted by the USLHC Project Office } \\
-\quad \text { Conceptual Design Review } \\
-\quad \text { Interim Design Review (if applicable) } \\
-\quad \text { Engineering Design Review } \\
-\quad \text { Production Readiness Review } \\
\text { - Internal peer Reviews conducted by the AFRD and Engineering } \\
\text { Divisions } \\
-\quad \text { Design reviews } \\
-\quad \text { Cost reviews } \\
-\quad \text { Project management reviews } \\
-\quad \text { Production reviews } \\
\text { Control of design documents (cf. Appendix C) } \\
-\quad \text { in LBNL Engineering Division System } \\
-\quad \text { in CERN EDMS }\end{array}$ \\
\hline Interf & $\begin{array}{l}\text { TAN/TAS and } \\
\text { DFBX design }\end{array}$ & $\begin{aligned} & \text { Interface Specifications } \\
&- \text { Define Interface Details and Responsibilities } \\
&- \text { Approved by CERN } \\
&- \text { Controlled by CERN EDMS }\end{aligned}$ \\
\hline Output & $\begin{array}{l}\text { TAN/TAS and } \\
\text { DFBX design }\end{array}$ & $\begin{array}{l}\text { Final documents are: } \\
\text { - Approved prior to issuance (generally at the EDR and PRR) } \\
\text { - Identified uniquely and by revision status } \\
\text { - } \text { Retained in LBNL Engineering Dept and CERN EDMS }\end{array}$ \\
\hline $\begin{array}{l}\text { Change } \\
\text { control }\end{array}$ & $\begin{array}{l}\text { TAN/TAS and } \\
\text { DFBX design }\end{array}$ & $\begin{array}{l}\text { Change control during the design process is assured by the use of } \\
\text { Intralink }{ }^{\circledR} \text { Software in conjunction with the Pro Engineer 3-d } \\
\text { CAD System. } \\
\text { Changes after the PRR are controlled by the CERN EDMS } \\
\text { process }\end{array}$ \\
\hline
\end{tabular}




\subsubsection{Procurement}

\begin{tabular}{|c|c|c|}
\hline Activity & Application & Controls \\
\hline Procurement planning & $\begin{array}{l}\text { High-cost items or } \\
\text { services }\end{array}$ & $\begin{array}{l}\text { Document procurement process to ensure } \\
\text { adequate consideration for ES\&H, cost and } \\
\text { schedule, quality assurance, security, and } \\
\text { compliance with codes and technical } \\
\text { specifications. } \\
\text { - Complete the Advance Acquisition Plan } \\
\text { (AAP) for procurements costing more than } \\
\text { \$100k. }\end{array}$ \\
\hline $\begin{array}{l}\text { Supplier and } \\
\text { subcontractor } \\
\text { selection }\end{array}$ & $\begin{array}{l}\text { Nonstandard and non- } \\
\text { off-the-shelf items or } \\
\text { services }\end{array}$ & $\begin{array}{l}\text { - Prepare selection criteria in accordance with } \\
\text { LBNL Procurement guidelines } \\
\text { - Objectively evaluate bidders' responses } \\
\text { - Document selection rationale. } \\
\text { - Periodically monitor to ensure continued } \\
\text { qualification. }\end{array}$ \\
\hline $\begin{array}{l}\text { Acceptance of items } \\
\text { and services }\end{array}$ & $\begin{array}{l}\text { Services and items } \\
\text { under contractual } \\
\text { agreement }\end{array}$ & $\begin{array}{l}\text { Document method of acceptance, which can } \\
\text { include: } \\
\text { - Inspection of Vendor Test Results } \\
\text { - LBNL Verification testing } \\
\text { - On-site Inspection of Vendor Operations } \\
\text { - Certificate of conformance } \\
\text { - Screening for suspect/counterfeit items } \\
\text { - Segregate non-accepted items from } \\
\text { satisfactory items. }\end{array}$ \\
\hline
\end{tabular}




\subsubsection{Inspection and Testing}

\begin{tabular}{|c|c|c|}
\hline Activity & Application & Controls \\
\hline Inspection & $\begin{array}{l}\text { Operations requiring } \\
\text { regular inspections, as } \\
\text { determined by line } \\
\text { management }\end{array}$ & $\begin{array}{l}\text { - Include inspections as part of written } \\
\text { operating procedures. } \\
\text { - } \text { Calibrate and maintain inspection } \\
\text { equipment. } \\
\text { - Establish inspection schedule. } \\
\text { - Identify acceptance criteria. } \\
\text { - Retain inspection reports and follow-up } \\
\text { actions. }\end{array}$ \\
\hline Testing & $\begin{array}{l}\text { - } \text { Bench tests } \\
\text { - Analytical laboratory } \\
\text { - Preoperational } \\
\text { - } \text { Maintenance } \\
\text { - Post-modification }\end{array}$ & $\begin{array}{l}\text { - Identify acceptance criteria. } \\
\text { - } \text { Calibrate and maintain testing equipment. } \\
\text { - } \text { Retain test results that verify process or } \\
\text { equipment are performing as specified. } \\
\text { - Place equipment test results on or near } \\
\text { equipment to signify status of equipment or } \\
\text { work process. }\end{array}$ \\
\hline $\begin{array}{l}\text { Follow-up on } \\
\text { nonconforming items }\end{array}$ & $\begin{array}{l}\text { Equipment or product } \\
\text { that failed an inspection } \\
\text { or test }\end{array}$ & $\begin{array}{l}\text { - Mark, tag, label, or post failure status on or } \\
\text { near equipment or product. } \\
\text { - Segregate nonconforming item if feasible. } \\
\text { - } \text { Retain retest or reinspection that documents } \\
\text { correction of the nonconforming item. }\end{array}$ \\
\hline
\end{tabular}

Specific LHC procedures and approaches for the handling of both procured and fabricated parts and assemblies are outlined in Appendix C

\subsubsection{Facility-Specific Controls}

The Berkeley Lab LHC-involved organization has the following facilityspecific controls in place: 


\subsection{Operating Practices}

\subsubsection{Facility Practices}

\begin{tabular}{|l|l|l|}
\hline \multicolumn{1}{|c|}{ Activity } & \multicolumn{1}{|c|}{ Application } & \multicolumn{1}{c|}{ Controls } \\
\hline $\begin{array}{l}\text { Emergency } \\
\text { procedures }\end{array}$ & All occupied facilities & $\begin{array}{l}\text { - Identify the facility supervisor. } \\
\text { - } \begin{array}{l}\text { Provide an emergency notification list with } \\
\text { work and home phone numbers and } \\
\text { alternate contacts. }\end{array}\end{array}$ \\
& & $\begin{array}{l}\text { - Have available an up-to-date building } \\
\text { emergency plan. }\end{array}$ \\
\hline $\begin{array}{l}\text { Communication } \\
\text { systems }\end{array}$ & All occupied facilities & $\begin{array}{l}\text { Regularly test emergency communication, } \\
\text { radios, and public address systems. }\end{array}$ \\
& & $\begin{array}{l}\text { Establish operating procedures for local } \\
\text { systems. } \\
\text { Ensure that posting and labeling in the } \\
\text { facility are managed. }\end{array}$ \\
\hline & &
\end{tabular}

\subsubsection{Asset Management}

\begin{tabular}{|c|c|c|}
\hline Activity & Application & Controls \\
\hline Traceability & $\begin{array}{l}\text { Equipment and other } \\
\text { items determined by } \\
\text { Berkeley Lab Property } \\
\text { Management as being } \\
\text { capital and sensitive } \\
\text { items and requiring } \\
\text { property control }\end{array}$ & $\begin{array}{l}\text { - Identify responsible person for each item } \\
\text { and piece of equipment requiring } \\
\text { accountability. } \\
\text { - Conduct periodic physical inventory. } \\
\text { - Trace equipment and items back to } \\
\text { specification, procurement records, } \\
\text { maintenance manual, and other support } \\
\text { documents. } \\
\text { - Identify and implement appropriate security } \\
\text { measures. }\end{array}$ \\
\hline Calibration & $\begin{array}{l}\text { Measuring and test } \\
\text { equipment (M\&TE) }\end{array}$ & $\begin{array}{l}\text { - Physically mark M\&TE with unique } \\
\text { identifier and recalibration due date. } \\
\text { - Calibrate at prescribed intervals and against } \\
\text { traceable standards. } \\
\text { - Specify limitations on range, accuracy, and } \\
\text { tolerance. } \\
\text { - } \text { Retain calibration records. }\end{array}$ \\
\hline Storage & $\begin{array}{l}\text { Physical assets with } \\
\text { moderate to high cost } \\
\text { value, hazard, or } \\
\text { operational importance }\end{array}$ & $\begin{array}{l}\text { - Verify any special equipment or protective } \\
\text { environment required for storage. } \\
\text { - Designate limited-access storage areas. } \\
\text { - Prevent damage, loss, or deterioration. }\end{array}$ \\
\hline Shipping and transfer & $\begin{array}{l}\text { Physical assets with } \\
\text { moderate to high cost } \\
\text { value, hazard, and/or } \\
\text { operational importance }\end{array}$ & $\begin{array}{l}\text { - Conform to packaging requirements. } \\
\text { - Verify that mode of transportation is } \\
\text { adequate. } \\
\text { - Retain shipping and transfer documents } \\
\text { (i.e., ensure traceability). }\end{array}$ \\
\hline
\end{tabular}




\title{
3.6 Documents and Records Management
}

To ensure the availability of accurate information from Berkeley Lab work processes and other activities related to LHC, documents and records are managed to provide for retention, preservation, retrievability, and assurance that the documents and records are current.

- Document control provisions ensure that only approved and up-to-date information pertaining to policy, prescribing work, specifying requirements, or establishing design criteria are available to users when needed. The LBNL-USLHC Project anticipates the following types of controlled documents:

\author{
Functional Specifications \\ Interface Specifications \\ Design Drawings \\ Engineering Notes \\ Safety Notes \\ Component Specifications \\ Fabrication Procedures \\ Assembly Procedures \\ Acceptance Plan \\ Test Procedures \\ Test Results and Travelers
}

Procedures for the control of these documents include the following:

\begin{tabular}{|l|l|l|}
\hline & \multicolumn{1}{|c|}{ Print } & \multicolumn{1}{|c|}{ Electronic } \\
\hline 1 & $\begin{array}{l}\text { Formal management review and } \\
\text { approval process to ensure that the } \\
\text { information is technically and } \\
\text { administratively adequate }\end{array}$ & $\begin{array}{l}\text { Formal management review and } \\
\text { approval process to ensure that the } \\
\text { information is technically and } \\
\text { administratively adequate }\end{array}$ \\
\hline 2 & $\begin{array}{l}\text { Coordination with Engineering Records } \\
\text { to print and distribute, as applicable }\end{array}$ & $\begin{array}{l}\text { Coordination with CERN to post } \\
\text { electronically to the CERN EDMS }\end{array}$ \\
\hline 3 & Documented user/distribution list & Access restricted to CERN EDMS users \\
\hline 4 & $\begin{array}{l}\text { Revision number or date on the } \\
\text { document }\end{array}$ & $\begin{array}{l}\text { Revision number or date on each } \\
\text { electronic file (section) of the document }\end{array}$ \\
\hline 5 & Return receipt & Not applicable \\
\hline 6 & Acknowledgment of destroying or & $\begin{array}{l}\text { Disclaimer on printed copies that the } \\
\text { electronic version is considered the }\end{array}$ \\
\hline
\end{tabular}




\begin{tabular}{|l|l|l|}
\hline & returning old controlled versions & official and controlled document \\
\hline 7 & $\begin{array}{l}\text { Archival of previous versions to the } \\
\text { Archives and Records Office }\end{array}$ & $\begin{array}{l}\text { Archival of electronic files by } \\
\text { Engineering Records }\end{array}$ \\
\hline
\end{tabular}

- Records Management ensures that records of completed activities are generated, maintained, and readily retrievable. Information and data that authenticate the organization's research, operational, or administrative activities are retained as evidence of completed work and adherence to standards and procedures. Most organizations will have records filed within their offices for easy retrieval. A records or file inventory must be established and maintained by the organization's administrative unit. Inactive records must be transmitted to the Berkeley Lab Archives and Records Office in accordance with retention and disposition requirements (see RPM 1.17).

Within three years after completion of the LBNL-USLHC Project tasks, the records will be turned over to the Berkeley Lab Archives and Records Office.

- Scientific and Technical Publications are processed through TEID's Report Coordination Office, which assigns report numbers, provides editing and printing services, and coordinates distribution. Publications receiving an LBNL, PUB, or LBID number must be reviewed by a qualified reviewer for content and further reviewed by the Report Coordination Office to ensure compliance with Berkeley Lab publication requirements (see RPM 5.02) and DOE requirements (DOE O 1430.2A).

\subsection{Standards and Requirements}

Section 2, Titled, Organization, of the LHC/QAP conforms to the following quality assurance criteria described in 10 CFR 830.120, Quality Assurance Requirements, and DOE O 414.1, Quality Assurance:

- Criterion 4, Documents and Records

- Criterion 5, Work Processes

- Criterion 6, Design

- Criterion 7, Procurement

- Criterion 8, Inspection and Acceptance Testing

Section 2 also complies with requirements described in paragraph 4 of DOE O 5480.19, Chg. 1, Conduct of Operations Requirements for DOE Facilities, and DOE P 450.4, Safety Management System Policy. 


\section{SECTION 4}

\section{PERFORMANCE ASSESSMENT AND IMPROVEMENT}

\subsection{Policy}

Berkeley Lab LHC-involved organizations must regularly evaluate work activities and improve the performance by:

- Conducting management assessments

- Conducting independent assessments

- Correcting deficiencies or improving processes, products, and services

\subsection{Management Assessment}

LHC-involved managers must regularly assess the performance of their organizations and functions to determine how well objectives and goals are being met. Assessments by line managers focus on identifying and resolving both singular and systematic management issues and problems that may hinder the organization in achieving its scientific and operational objectives. Managers should assess their processes for the following:

- Planning

- Organizational interfaces (internal and external to the organization)

- Integration of management systems (e.g., quality, safety, security )

- Use of performance metrics

- Training and qualifications

- Supervisory oversight and support

When applicable, the management assessments should include an evaluation of such conditions as the state of employee knowledge, motivation, and morale; communication among workers; the existence of an atmosphere of creativity and improvement; and the adequacy of human and material resources. The assessments should also involve direct observation of work so that the manager is aware of the interactions at a work location. The observations can be supplemented with worker and customer interviews, safety and performance documentation reviews, and drills or exercises. 
The documentation can include minutes of staff and operations meetings, progress reports, job expectation evaluations, inspection reports, and selfassessment reports.

The LBNL-USLHC Project issues monthly reports which give technical progress, technical issues, monthly costs, and earned value analysis. The reports are sent to the USLHC Project Office for incorporation into the entire USLHC Project Progress Report.

\subsection{Independent Assessment}

\subsubsection{Independent Assessment}

Independent assessments advise the LHC-involved managers on the quality of products, services, and processes produced by or for the organization. The type and frequency of independent assessments are based on the status, complexity, risk, and importance of the activities or processes being assessed. The assessments are performed by technically and programmatically knowledgeable personnel within Berkeley Lab who are free of direct responsibility in the areas they assess. The lead assessors must work for organizations that have sufficient authority and independence to gain access to senior Lab managers capable of directing LHC-involved organizations to take actions in response to the assessment results. Berkeley Lab organizations that routinely conduct independent assessments include the Environment, Health and Safety Division; the Internal Audit Services Department; the Office of Assessment and Assurance; and the Safety Review Committee. Each assessment organization has established protocols for conducting assessments and providing feedback to the assessed organizations.

Independent assessments include:

- Evaluating work performance and process effectiveness

- Evaluating compliance to the management system requirements

- Identifying abnormal performance and potential problems

- Identifying opportunities for improvement

- Documenting and reporting results

- Verifying satisfactory resolutions of reported problems

The work of the LBNL-USLHC Project is assessed by a series of design reviews conducted by the USLHC Project Office at FNAL. These reviews consist of the Conceptual Design Review, a possible Interim Design Review, Engineering Design Review, Production Readiness Review and a possible Pre-Assembly Review. In addition, the USLHC Project may call upon personnel outside LBNL to perform reviews of targeted items such as detail design drawings. Lastly, LBNL may conduct in-depth internal reviews of selected topics such as reviews of cost estimates.

In addition, LBNL is expected to participate in DOE-conducted reviews of the USLHC Project on a regular basis. 


\subsection{Continuous Improvement}

Continuous improvement is a combination of quality improvement and corrective actions that (1) uses feedback information to improve processes, products, and services; (2) prevents or minimizes quality or safety problems; and (3) when discovered, correct the problems that occur. A quality or safety problem is a collective term that involves a deficiency in an activity, product, service, item characteristic, or process parameter; in an environment, safety, and health requirement; or in a legal and contractual requirement. LHCinvolved managers have the responsibility to correct deficiencies and improve whenever possible on the processes, products, and services under their supervision.

\subsubsection{Quality Improvement}

Improvement in quality is a disciplined management process based on the premise that all work can be planned, performed, measured, and improved. LHC-involved managers should ensure that the focus is on improving the quality of processes, products, and services by establishing priorities, promulgating policy, promoting cultural aspects, allocating resources, communicating lessons learned, and resolving significant management issues and problems that hinder the organization from achieving its objectives. Management must balance safety and mission priorities when considering improvement actions.

A quality improvement process includes:

- Reviewing information and data on processes, products, or services to identify conditions adverse to quality and safety

- Analyzing the adverse conditions and determining the causes

- Segregating the processes, products, or services if the adverse conditions may lead to significant consequences, as determined by line management

- Developing alternative approaches for addressing the adverse conditions and preventing recurrence (e.g., reducing process variability or cycle time)

- Implementing the approved solutions

- Evaluating the improvements or corrections

- Providing lessons learned to other organizations

The quality improvement process is part of the normal operation of Berkeley Lab LHC-involved organizations and is documented in the normal operational records and reports (e.g., minutes from staff and operations meetings; progress and activity reports; readiness reviews; assessment and inspection reports). Conditions that have significant adverse consequences have separate disposition reports that document the actions taken to correct the problems. 


\subsection{Standards and Requirements}

Section 3 of the LHC/QAP conforms to the following quality assurance criteria described in 10 CFR 830.120, Quality Assurance Requirements, and DOE O 414.1, Quality Assurance:

- Criterion 3, Quality Improvement

- Criterion 9, Management Assessment

- Criterion 10, Independent Assessment

Section 3 also complies with requirements described in paragraph 4 of DOE O 5480.19, Chg. 1, Conduct of Operations Requirements for DOE Facilities, and DOE P 450.4, Safety Management System Policy. 


\section{Graded Approach Methodology at Berkeley Lab}

\section{A.1 Introduction}

A graded approach is used to determine the rigor with which the requirements of the Operating and Assurance Program (OA Program) should be applied to a given Laboratory activity. The objective of the graded approach is to ensure that work activities are managed through systems adequate and commensurate with the risk involved in the activity. Risks include potential impact to public health and safety, threats to the environment, consequences of noncompliance, and cost impacts.

The text that follows describes one method of assessing hazards and risks in order to grade processes, activities, or facilities. Alternate methodologies, such as the use of DOE guidance documents or evaluation of existing hazard documentation, may be used if the rationale is appropriately documented and approved.

\section{A.2 Methodology}

- Line management defines the facilities and functions for which it is responsible. These definitions should include a characterization of the ongoing activities performed, space and types of equipment used, and personnel involved (both Berkeley Lab and non-Berkeley Lab).

- Activity associated with a facility or function is analyzed to determine the level of risk it entails. Risk is a function of the negative consequence that may result if an appropriate level of management control is not applied to prevent these negative consequences. The analysis is performed by considering the eight risk-potential categories described in Table A-1. The categories are consistent with those contained in the Berkeley Lab Risk-Based Priority Planning Grid.* Three sets of consequence statements are provided for each category: high risk $(\mathrm{H})$, moderate risk (M), and low risk (L).

- Critical to assessing risk is the probability that an event will occur. In analyzing the risk inherent in each activity, one must estimate the likelihood that the potential risk level may be encountered. Operating experience, commonly accepted statistical probabilities, bestmanagement information, or other relevant data can be used to estimate the likelihood of the worst-case scenario. Care should be taken to consider cost-effectiveness when developing management controls for an

\footnotetext{
*Note: The Berkeley Lab Grid is based on the Risk Prioritization Methodology contained in the DOE-EH 5-Year Safety and Health Planning Guidance.
} 
event. Laboratory line managers should balance the probability of an event occurring with the potential consequence (or cost) of achieving an effective set of such controls.

- Based on this risk analysis, line management determines the rigor to use in applying the OA Program requirements to their operations. This approach will result in determining the degree to which documentation and training are to be implemented. The line organization then has documentation as to why one or more activities within a facility or function have a high level of rigor (e.g., a detailed written procedure) while others rely on standard operating procedures or guidelines (e.g., RPM, PUB-3000, or standard laboratory, shop, or business practices).

- As conditions change, as a result of the self-assessment process, or as performance problems are identified, the graded approach for each facility and function is reviewed to determine whether OA Program requirements continue to be met in an appropriate and cost-effective manner. 
Table A-1: Risk Potential Analysis Using the Berkeley Lab Priority Planning Grid

Within each risk category, a statement is selected that best characterizes the potential consequence of a failure to apply quality assurance principles to a particular activity.

\begin{tabular}{|c|c|c|c|c|}
\hline \multirow{2}{*}{\multicolumn{2}{|c|}{ RISK CATEGORY }} & \multicolumn{3}{|c|}{ CONSEQUENCE CATEGORY } \\
\hline & & High & Moderate & Low \\
\hline $\begin{array}{l}E \\
S \\
\&\end{array}$ & Public safety & $\begin{array}{l}\text { Loss of life or serious } \\
\text { injury; exposure to } \\
\text { hazardous materials in } \\
\text { excess of standards }\end{array}$ & $\begin{array}{l}\text { Reportable non-process- } \\
\text { related accident }\end{array}$ & \begin{tabular}{|l} 
Minor \\
nonreportable \\
events
\end{tabular} \\
\hline $\begin{array}{l}\mathrm{H} \\
\mathrm{A} \\
\mathrm{Z} \\
\mathrm{A}\end{array}$ & $\begin{array}{l}\text { Researcher and staff } \\
\text { safety }\end{array}$ & $\begin{array}{l}\text { Loss of life or serious } \\
\text { injury; exposure to } \\
\text { hazardous materials in } \\
\text { excess of standards }\end{array}$ & $\begin{array}{l}\text { Reportable onsite work } \\
\text { accident; exposure near } \\
\text { acceptable limits }\end{array}$ & $\begin{array}{l}\text { Minor events not } \\
\text { resulting in } \\
\text { hospitalization; } \\
\text { exposures below } \\
20 \% \text { of limits }\end{array}$ \\
\hline $\mathrm{D}$ & $\begin{array}{l}\text { Environmental } \\
\text { protection }\end{array}$ & $\begin{array}{l}\text { Serious damage to the } \\
\text { environment }\end{array}$ & $\begin{array}{l}\text { Release of hazardous } \\
\text { material exceeding } \\
\text { established limits; } \\
\text { repairable damage } \\
\end{array}$ & \begin{tabular}{|l|} 
Unplanned release \\
within established \\
limits; minor \\
reportable events \\
\end{tabular} \\
\hline $\begin{array}{l}\mathrm{E} \\
\mathrm{G} \\
\mathrm{U} \\
\mathrm{L}\end{array}$ & $\begin{array}{l}\text { Compliance with law, } \\
\text { contract agreement, } \\
\text { regulation }\end{array}$ & $\begin{array}{l}\text { Noncompliance with } \\
\text { laws or regulations } \\
\text { with possible penalties }\end{array}$ & $\begin{array}{l}\text { Minor technical or } \\
\text { administrative } \\
\text { violation(s) }\end{array}$ & $\begin{array}{l}\text { Little or no adverse } \\
\text { regulatory results }\end{array}$ \\
\hline $\begin{array}{l}\text { A } \\
\mathrm{T} \\
\mathrm{O} \\
\mathrm{R}\end{array}$ & $\begin{array}{l}\text { Best management } \\
\text { practice }\end{array}$ & & $\begin{array}{l}\text { Significant deviation } \\
\text { from good practice }\end{array}$ & $\begin{array}{l}\text { Minor deviation } \\
\text { or slow } \\
\text { implementation }\end{array}$ \\
\hline $\begin{array}{l}P \\
R \\
O \\
\text { G } \\
\text { R } \\
\text { A }\end{array}$ & $\begin{array}{l}\text { Berkeley Lab mission/ } \\
\text { programmatic } \\
\text { impact/Berkeley Lab } \\
\text { support services }\end{array}$ & $\begin{array}{l}\text { Failure to meet critical } \\
\text { milestone; could lead } \\
\text { to Berkeley Lab } \\
\text { shutdown; non- } \\
\text { delivery of significant } \\
\text { services; results in } \\
\text { corrective action by } \\
\text { DOE }\end{array}$ & $\begin{array}{l}\text { Failure to meet internal } \\
\text { DOE program } \\
\text { commitments; high- } \\
\text { impact service } \\
\text { reductions }\end{array}$ & $\begin{array}{l}\text { Minor degradation } \\
\text { in performance, } \\
\text { cost, or schedule }\end{array}$ \\
\hline $\begin{array}{l}\text { M } \\
\text { A } \\
\mathrm{T} \\
\mathrm{I}\end{array}$ & Laboratory protection & $\begin{array}{l}\text { Facility or equipment } \\
\text { damage }>\$ 500 \mathrm{k}\end{array}$ & $\begin{array}{l}\text { Facility or equipment } \\
\text { damage }<\$ 500 \mathrm{k} ; \\
\text { increased operations } \\
\text { cost to } \$ 250 \mathrm{k}\end{array}$ & $\begin{array}{l}\text { Equipment damage } \\
\text { or operations cost } \\
\text { to } \$ 50 \mathrm{k}\end{array}$ \\
\hline $\mathrm{C}$ & Public perception & $\begin{array}{l}\text { National press } \\
\text { coverage; public } \\
\text { demonstrations }\end{array}$ & $\begin{array}{l}\text { Local press coverage; } \\
\text { some public concern by } \\
\text { special-interest groups }\end{array}$ & $\begin{array}{l}\text { Little or no public } \\
\text { concern }\end{array}$ \\
\hline
\end{tabular}




\section{Principal LBNL US-LHC Project Staff}

The LBNL US-LHC Project Staff includes:

\begin{tabular}{|c|c|c|}
\hline Role & Duty & Name \\
\hline Project Manager & Overall Responsibility & W. C. Turner ${ }^{b}$ \\
\hline $\begin{array}{l}\text { Deputy Project } \\
\text { Manager }\end{array}$ & $\begin{array}{c}\text { DFBX } \\
\text { Project Management }\end{array}$ & J.E. Rasson ${ }^{\mathrm{ab}}$ \\
\hline $\begin{array}{l}\text { Superconductor } \\
\text { Manager }\end{array}$ & $\begin{array}{c}\text { Provide cable and } \\
\text { support to FNAL and } \\
\text { CERN }\end{array}$ & R. M. Scanlan \\
\hline Tan/TAS Engineer & $\begin{array}{l}\text { Design, Fabricate, \& } \\
\text { Test TAS/TAN }\end{array}$ & W. J. Elliott ${ }^{\mathrm{ab}}$ \\
\hline $\begin{array}{l}\text { DFBX Lead } \\
\text { Engineer }\end{array}$ & $\begin{array}{c}\text { Overall technical } \\
\text { Responsibility for the } \\
\text { DFBX }\end{array}$ & J. Zbasnik ${ }^{\mathrm{a}}$ \\
\hline
\end{tabular}

a. Matrixed to the LHC Project from the Mechanical Engineering Department

b. Project Controller as defined in Cern Quality Assurance ProcedureLHC-PM-QA-303.00. 


\section{LHC QA Procedures for Procurement, Fabrication, Assembly, and Testing}

\section{C.1 Scope}

During all stages of the LBNL LHC project from procurement through delivery at CERN of all deliverables, specific procedures shall be followed. These procedures are designed help to ensure that the deliverables meet the functional requirements, interface specifications, and overall quality.

Emphasis is being placed on moving to an electronic documentation of all parts and assemblies during production. Nothing in this procedure limits the use of such electronic information systems provided that documentation provides a sufficiently secure and reliable record of the condition of parts and assemblies.

\section{C.2 Design Control and Nomenclature}

Figure C-1 shows the LBNL LHC design control and release flow of controlled project documents. The dashed rectangle surround work in progress [WIP] on documents that are in development. Berkeley Lab documents submitted to CERN use templates specificed in CERN Quality Assurance Procedure LHC-PM-QA-405.00. 


\section{C.2.1 Design Document Flow}

\section{LHC DESIGN CONTROL/RELEASE PROCESS}

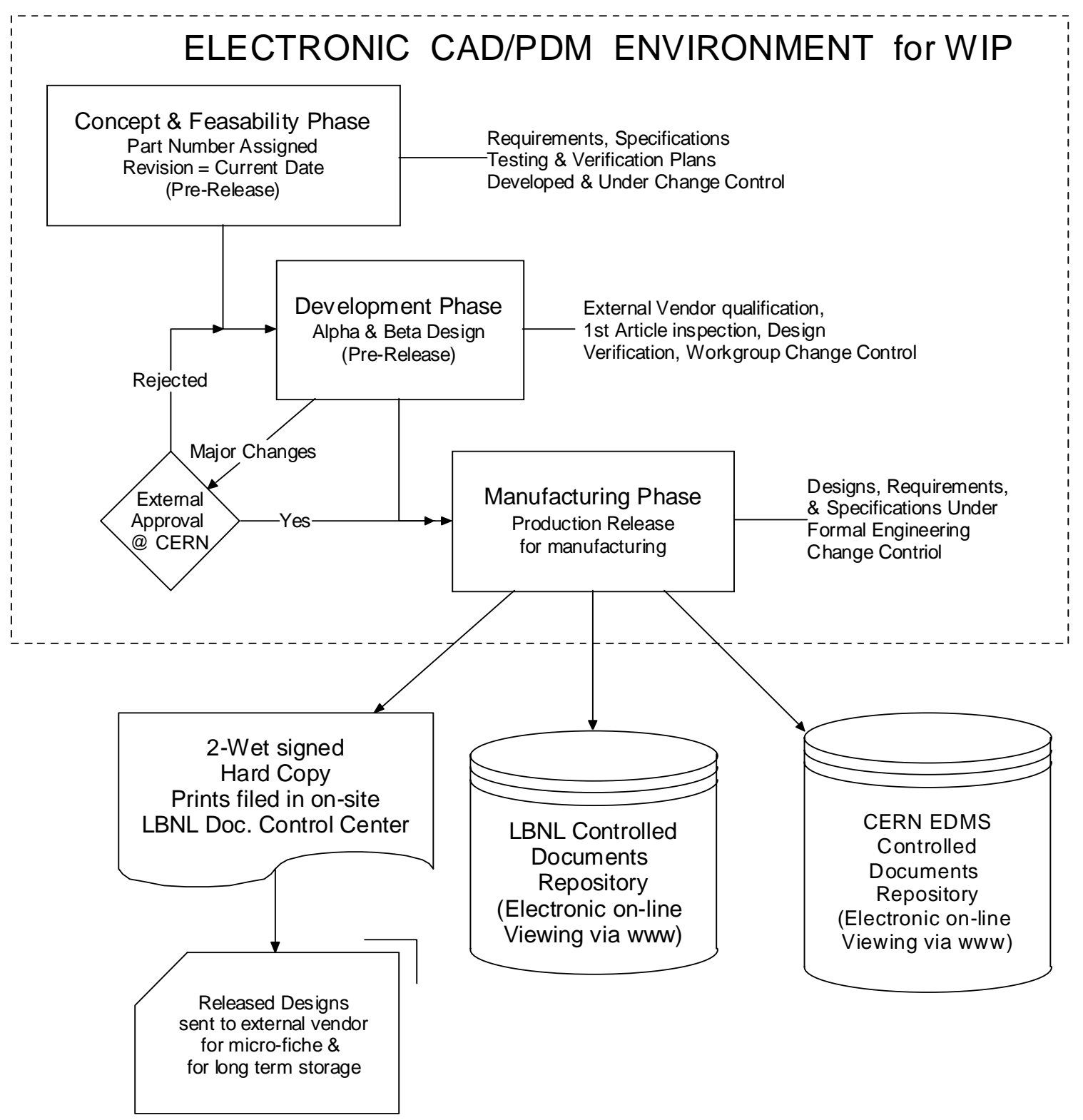

Figure C-1 LBNL Design Control Flow 


\section{C.2.2 Part Naming Convention}

The LBNL LHC project uses a naming convention that includes the Machine Code, Equipment Code and Sequential Code for part naming. This is the standard process used to track assemblies and parts at LBNL. This allows for sorting, searching, and archiving of records based on machine, specific subsections of machines or individual part numbers.

\begin{tabular}{|l|l|l|}
\hline Machine Code & Equipment Code & Sequential Number \\
\hline XX & XXXX & 12 X3456 \\
\hline
\end{tabular}

\section{C.3 Inspection}

\section{C.3.1 Procured Parts and Assemblies}

All parts/assemblies received through outside procurement shall be identified in a manner so that specific inspection records may be tied specific parts/assemblies where required.

All parts/assemblies received through outside procurement shall be inspected to ensure that they conform to the drawings, specifications, and requirements that were part of the procurement contract established with the supplier of the part/assembly.

A unique electronic or physical signature or stamp on either a specific physical or electronic inspection report, traveler, or inspection drawing shall document the inspection.

\section{C.3.2 LBNL Fabricated Parts/Assemblies}

All parts/assemblies fabricated within LBNL shall be identified in a manner so that specific inspection records may be tied specific parts/assemblies where required.

All parts/assemblies fabricated within LBNL shall be inspected to ensure that they conform to the drawings, specifications, and requirements that were part of the work order, traveler, or assembly procedure established for that respective part/assembly.

A unique electronic or physical signature or stamp on either a specific physical or electronic inspection report, traveler, or inspection drawing shall document the inspection. 


\section{C.4 Non-Conformance}

Any part/assembly found to be in non-conformance with the drawings, specifications, requirements, traveler, or assembly procedure shall be identified as being non-conforming and separated for disposition determination by the Material Review Board governing that portion of the LBNL LHC Deliverables.

Tags or other identification of non-conformance of a part or assembly may only be removed subsequent to release of the part/assembly by the Material Review Board.

\section{C.5 Material Review Board}

\section{C.5.1 Purpose}

The Material Review Board (MRB) is constituted to determine the disposition of non-conforming parts/assemblies, and to institute and approve corrective or remedial action where required.

\section{C.5.2 Membership}

The MRB for TAS/TAN Absorbers shall be composed of the TAS/TAN Absorbers Lead Engineer and the LBNL LHC Project Manager. In the absence of the LBNL Project Manager, the LBNL LHC Deputy Project Manager serves in his stead. The TAS/TAN Absorbers Lead Engineer shall designate an alternate to serve in his absence.

The MRB for DFBX shall be composed of the DFBX Lead Engineer, the LBNL LHC Deputy Project Manager, and the LBNL LHC Project Manager. Any two of the three members of the DFBX MRB may constitute a quorum, but alternates shall be designated to ensure the timely consideration and disposition of parts/assemblies.

The MRB can have its deliberations in person, by telephone, e-mail, or even sequentially should circumstances dictate.

\section{C.5.3 Considerations}

The MRB will be convened to consider non-conforming parts/assemblies and to determine a disposition of those parts. The MRB may choose from the following dispositions: use as is, repair/rework, or scrap. The MRB may also determine that the underlying control documentation requires modification.

\section{C.5.3.1 Use As Is}

If the MRB makes the determination that the non-conforming part/assembly does not adversely impact the form, fit, or function in its present configuration, it may be designated "USE AS IS) on the Inspection report or traveler and signed and dated by the MRB. The nature of the discrepancy and the assembly within which the part is used is documented and becomes part of the "as-built" documentation. 


\section{C.5.3.2 Rework}

If the MRB makes the determination that the non-conforming part/assembly may be modified so that it does not adversely impact the form, fit, or function, it may be designated "Rework") on the Inspection report or traveler and signed and dated by the MRB. The specific aspects of the nonconforming part that require rework are noted and form the basis of the inspection after the part has been reworked. The aspects of the discrepancy and its reworked configuration are documented and become part of "as-built" documentation.

\section{C5.3.3 Scrap}

If the MRB makes the determination that the non-conforming part can neither be used as-is or reworked, or that the form, fit, or function of the assembly/system will be compromised by the use of the part, the part will declared as scrap. Any part/assembly declared; as scrap will be immediately segregated from any conforming parts/assemblies and modified or identified as to unambiguously identify it as scrap. The part/assembly will be disposed/recycled and care shall be exercised to ensure that no possibility of use of the part in the LHC assembly.

\section{C.5.3.4 Modification of Documentation}

If the MRB makes the determination that the non-conformance or dysfunction of the part or assembly is the result of errors or omissions within the underlying controlling documentation, the MRB may designate that the documentation be modified, updated, or corrected to remove the discrepancy. The modification of the underlying controlled documentation shall be done in accordance with the control and release aspects as dictated by the LBNL Engineering Standards for controlled documentation, drawings, or specifications. The non-conforming or dysfunctional part shall be evaluated with respect to the pending modifications. The non-conforming part/assembly will then be designated as in conformance, use as is, reworked or scrap based on the pending document change notices.

If the documentation involves footprint or interface specifications the LHC and US-LHC project offices will be involved as is required.

\section{C.6 Change Control}

Any determination by the MRB that requires a modification of underlying design documentation, or through repair/rework or use-as-is shall be classified as a Minor Change or a Major Change. A Major Change is a change that involves the review/approval of either the US-LHC or CERNLHC project offices. Examples of Major Changes would be a change impacting a footprint or interface or general specification/requirement previously established by multiple entities. A Minor Change are all other changes and do not involve multiple entities or subsystems. 
The directives of the MRB shall constitute the Engineering Change Request (ECR) and once approved, with those approvals, shall constitute the Engineering Change Notice (ECN).

Should, during the course of manufacture or assembly, a change to assembly procedure, traveler, or fabrication approach become warranted, such a change shall be handled with the same approach and system as actions of the MRB and subject to the same approval and documentation levels including ECR and ECNs.

\section{C.7 Audits}

The General Sciences Project Office [GS Projects] remains accountable to the Accelerator and Fusion Research Division in ensuring that adequate procedures and steps are being taken during the development, execution and production of projects within AFRD at Berkeley Labs. Consequently, GS Projects shall be allowed access on a formal or informal basis, as it deems appropriate, to audit and assess the implementation of quality assurance procedures within the LBNL LHC project. 
Appendix D

\section{Integrated Safety Management (ISM)}

Table D-1. Seven ISM Guiding Principles

\begin{tabular}{|c|c|c|}
\hline ISM Provision & Resource/Policy References & Sample Mechanisms \\
\hline $\begin{array}{l}\text { Line management is responsible } \\
\text { for the protection of the public, } \\
\text { the workers, and the environment. }\end{array}$ & $\begin{array}{l}\text { RPM, Chap. } 7 \\
\text { PUB-3000, Chap. } 1 \& 6 \\
\text { LHC/QAP, Section } 1.2\end{array}$ & $\begin{array}{l}\text { - Organization charts (roles and } \\
\text { responsibilities) } \\
\text { - Position descriptions }\end{array}$ \\
\hline $\begin{array}{l}\text { Clear and unambiguous lines of } \\
\text { authority and responsibility for } \\
\text { ensuring safety are established } \\
\text { and maintained. }\end{array}$ & $\begin{array}{l}\text { RPM, Chap. } 7 \\
\text { PUB-3000, Chap. } 1 \& 6 \\
\text { LHC/QAP, Section } 1.2\end{array}$ & $\begin{array}{l}\text { - Organization charts (roles and } \\
\text { responsibilities) } \\
\text { - Position descriptions } \\
\text { - Authorizations via SADs, } \\
\text { AHDs, RWAs, and division- } \\
\text { approved protocol }\end{array}$ \\
\hline $\begin{array}{l}\text { Personnel possess the experience, } \\
\text { knowledge, skills, and abilities } \\
\text { necessary to discharge their } \\
\text { responsibilities. }\end{array}$ & $\begin{array}{l}\text { RPM, Section } 2.01 \\
\text { LHC/QAP, Section } 1.4 \\
\text { PUB-3000, Chap. } 24\end{array}$ & $\begin{array}{l}\text { - Position descriptions } \\
\text { - } \mathrm{P}^{2} \mathrm{R} \text { performance evaluations } \\
\text { - Authorizations via SADs, } \\
\text { AHDs, RWAs, and division- } \\
\text { approved protocol } \\
\end{array}$ \\
\hline $\begin{array}{l}\text { Resources are effectively } \\
\text { allocated to address safety, } \\
\text { programmatic, and operational } \\
\text { considerations. }\end{array}$ & $\begin{array}{l}\text { LHC/QAP, Section } 1.3 \\
\text { Self-Assessment Manual }\end{array}$ & $\begin{array}{l}\text { - Work plans } \\
\text { - Research proposals (e.g., WFO, } \\
\text { FTP) } \\
\text { - NEPA/CEQA } \\
\text { - Division Safety Coordinators' } \\
\text { self-assessment/MESH } \\
\end{array}$ \\
\hline $\begin{array}{l}\text { Before work is performed, the } \\
\text { associated hazards are evaluated } \\
\text { and an agreed-upon set of safety } \\
\text { standards and requirements is } \\
\text { established. }\end{array}$ & $\begin{array}{l}\text { PUB-3000 } \\
\text { LHC/QAP, Section } 2.3\end{array}$ & $\begin{array}{l}\text { - Authorizations via SADs, } \\
\text { AHDs, RWAs, and division- } \\
\text { approved protocol } \\
\text { - NEPA/CEQA } \\
\text { - EH\&S functional programs }\end{array}$ \\
\hline $\begin{array}{l}\text { Administrative and engineering } \\
\text { controls to prevent and mitigate } \\
\text { hazards are tailored to the work } \\
\text { being performed and associated } \\
\text { hazards. }\end{array}$ & $\begin{array}{l}\text { PUB-3000 } \\
\text { LHC/QAP, Section } 2.3 \& 2.4\end{array}$ & $\begin{array}{l}\text { - Authorizations via SADs, } \\
\text { AHDs, RWAs, and division- } \\
\text { approved protocol } \\
\text { - NEPA/CEQA } \\
\text { - EH\&S functional programs }\end{array}$ \\
\hline $\begin{array}{l}\text { The conditions and requirements } \\
\text { to be satisfied for operations to be } \\
\text { initiated and conducted are clearly } \\
\text { established and agreed upon. }\end{array}$ & $\begin{array}{l}\text { PUB-3000 } \\
\text { LHC/QAP, Section } 2.1\end{array}$ & $\begin{array}{l}\text { - Authorizations via SADs, } \\
\text { AHDs, RWAs, and division- } \\
\text { approved protocol } \\
\text { - NEPA/CEQA }\end{array}$ \\
\hline
\end{tabular}


Table D-2. Five ISM Core Functions

\begin{tabular}{|c|c|c|}
\hline ISM Function & Resource/Policy References & Sample Mechanisms \\
\hline Define the scope of work. & LHC/QAP, Section 2.2 & $\begin{array}{l}\text { - Work plans } \\
\text { - Research proposals (e.g., } \\
\text { WFO, FTP) } \\
\text { - NEPA/CEQA } \\
\text { - Authorizations via SADs, } \\
\text { AHDs, RWAs, and } \\
\text { division-approved protocol }\end{array}$ \\
\hline $\begin{array}{l}\text { Identify and analyze hazards } \\
\text { associated with the work. }\end{array}$ & $\begin{array}{l}\text { PUB-3000 } \\
\text { LHC/QAP, Section } 2.3\end{array}$ & $\begin{array}{l}\text { - Work plans } \\
\text { - Research proposals (e.g., } \\
\text { WFO, FTP) } \\
\text { • NEPA/CEQA } \\
\text { - Authorizations via SADs, } \\
\text { AHDs, RWAs, and } \\
\text { division-approved protocol }\end{array}$ \\
\hline $\begin{array}{l}\text { Develop and implement } \\
\text { hazard control. }\end{array}$ & $\begin{array}{l}\text { PUB-3000 } \\
\text { LHC/QAP, Section } 2.3 \& 2.4\end{array}$ & $\begin{array}{l}\text { - Work plans } \\
\text { - Research proposals (e.g., } \\
\text { WFO, FTP) } \\
\text { - NEPA/CEQA } \\
\text { - Authorizations via SADs, } \\
\text { AHDs, RWAs, and } \\
\text { division-approved protocol } \\
\text { - Self-assessment } \\
\end{array}$ \\
\hline Perform work within controls. & $\begin{array}{l}\text { PUB-3000 } \\
\text { LHC/QAP, Section } 2.3 \& 2.4\end{array}$ & $\begin{array}{l}\text { - Work plans } \\
\text { - Research proposals (e.g., } \\
\text { WFO, FTP) } \\
\text { • NEPA/CEQA } \\
\text { - Authorizations via SADs, } \\
\text { AHDs, RWAs, and } \\
\text { division-approved protocol }\end{array}$ \\
\hline $\begin{array}{l}\text { Provide feedback on adequacy } \\
\text { of controls, and continue to } \\
\text { improve safety management. }\end{array}$ & $\begin{array}{l}\text { Self-Assessment Manual } \\
\text { LHC/QAP, Section } 3\end{array}$ & $\begin{array}{l}\text { - Self-assessment } \\
\text { - Integrated functional } \\
\text { appraisals } \\
\text { - IASA appraisals } \\
\end{array}$ \\
\hline
\end{tabular}




\section{Policy and Procedure for Controlling Suspect/Counterfeit Items}

A suspect item is one in which there is an indication by visual inspection, testing, or other information that it may not conform to established government or industry-accepted specifications or national consensus standards. A counterfeit item is a suspect item that is a copy or substitute without legal right or authority to do so, or one whose material, performance, or characteristics are knowingly misrepresented by the vendor, supplier, distributor, or manufacturer. The use of suspect/counterfeit items (S/CIs) can lead to unexpected failures and undue risk of mission impacts, environmental impacts, and personal injury, contamination, or death. For these reasons, Berkeley Lab has instituted mitigating measures for the prevention, detection, and disposition of S/CIs at the Laboratory.

\section{E.1 Identification}

The range of items at the Laboratory that should be considered as possible S/CIs includes the following:

- High-strength fasteners (bolts, screws, nuts, and washers)

- Electrical/electronic components: circuit breakers, current and potential transformers, fuses, resistors, switch gear, overload and protective relays, motor control centers, heaters, motor generator sets, DC power supplies, AC inverters, transmitters, computer components, semiconductors

- $\quad$ Piping components: fittings, flanges, valves and valve replacement products, couplings, plugs, spacers, nozzles, pipe supports

- $\quad$ Pre-formed metal structures, elastomers (O-rings, seals), spare/replacement kits from suppliers other than original equipment manufacturers, weld filler material, diesel generator speed governors and pumps

DOE maintains a list of S/CIs and identification guidance on the DOE web site at http://www.sci.doe.gov.

\section{E.2 Procurement}

1. Any item known as counterfeit in the past (e.g., Grades 5 and 8 highstrength bolts, circuit breakers, and other S/CIs listed on the DOE S/CI web site) should be procured only from qualified or dedicated suppliers, particularly items intended for use in safety systems or critical applications. The Berkeley Lab Procurement Department can qualify suppliers and provide technical specifications and quality clauses prohibiting delivery of S/CIs in the purchase orders and contracts. 
2. High-strength fasteners (graded bolts, screws, nuts, and washers) must be purchased directly through the Procurement Department. Procurement buyers will purchase from prequalified suppliers and will retain the manufacturer's certificate of conformance and/or certified material test report. Once on site, high-strength fasteners must be segregated and secured from the general stock to eliminate mixing with non-graded fasteners and to prevent general use.

3. On-site stores, shops, and end users should inspect newly received items known as counterfeit in the past. S/CI identification guidance is provided on the DOE S/CI web site. Periodic inspection of open stock and storage areas should continue to ensure they have been purged of S/CIs.

\section{E.3 Installed Items}

1. During routine Laboratory inspections of facilities and equipment (e.g., self-assessment, EH\&S functional inspections, maintenance and construction inspections), consideration should be given to identify S/CIs (identification guidance provided on the DOE S/CI web site). Additional training for personnel to recognize S/CIs can be arranged through the Office of Assessment and Assurance (OAA) in the Environment, Health and Safety Division.

2. If an installed item is suspected of being a S/CI, OAA must be contacted to coordinate any engineering evaluation, verification testing, or disposition process.

3. If it is determined that the $\mathrm{S} / \mathrm{CI}$ in safety systems and critical applications (e.g., heavy equipment, critical load paths in lifting equipment, and facility structures) can adversely affect the environment or create a safety hazard, the system or application must be locked/tagged out and the S/CI removed and replaced. If there is no adverse affect or creation of a hazard, the S/CI must be identified and entered into the Division's Laboratory Self-Assessment Database (LSAD), and either removed and replaced during routine maintenance or determined to remain in place. If the $\mathrm{S} / \mathrm{CI}$ is to remain in place, the structure or equipment must be tagged or marked, and the LSAD entry so annotated and closed out.

4. For non-safety systems and non-critical applications, the S/CI must be identified and entered into LSAD, and either removed and replaced during routine maintenance or determined to remain in place. If the S/CI is to remain in place, the structure or equipment must be tagged or marked, and the LSAD entry so annotated and closed out.

\section{E.4 Disposition and Reporting}

1. If an $\mathrm{S} / \mathrm{CI}$ requires removal, OAA must coordinate and document the disposition. S/CIs must be removed from the work/use site and transferred to the LBNL Warehouse to be temporarily stored in a segregated area. Efforts will be made by the Procurement Department to 
identify the supplier, manufacturer, or distributor to seek restitution for the Laboratory.

2. OAA must report all discovered S/CIs to the local DOE Office of Inspector General (OIG) and the cognizant DOE operations office manager by means of the Occurrence Reporting and Processing System (ORPS).

3. After the $\mathrm{S} / \mathrm{CI}$ is no longer needed as material evidence by OIG, the LBNL Warehouse will coordinate the destruction or alteration of the $\mathrm{S} / \mathrm{CI}$ to render them unusable. 